\title{
A INDÚSTRIA CULTURAL E A AQUISIÇÃO DO CRÉDITO PELO IDOSO: UMA RAZÃO PARA O SUPERENDIVIDAMENTO
}

\author{
Carlos Gustavo Chada Chaves ${ }^{1}$ \\ Ivy Helene Lima Pagliusi ${ }^{2}$ \\ Kátia Borges dos Santos ${ }^{3}$
}

RESUMO: Em tempos de pós-modernidade, o que se vê é que os hábitos de consumo não são manifestações espontâneas dos indivíduos, mas verdadeiras imposições determinadas pela indústria cultural. O presente artigo tem como objetivo demonstrar que a indústria cultural é capaz de determinar o comportamento de um público específico de consumidores, os idosos, à aquisição irresponsável de crédito, de forma a conduzi-los ao superendividamento. O método a ser utilizado será o dedutivo e a pesquisa será feita em bibliografia nacional.

Palavras-Chave: Indústria cultural. Consumidor idoso. Crédito. Superendividamento.

\section{CULTURAL INDUSTRY AND ACQUISITION OF CREDIT BY THE ELDERLY: A REASON FOR SUPERENDIVIDITY}

ABSTRACT: In post-modern times, what we see is that consumption habits are not spontaneous manifestations of individuals, but real impositions determined by the cultural industry. This article aims to demonstrate that the cultural industry is able to determine the behavior of a specific audience of consumers, the elderly, towards irresponsible credit acquisition, in order to lead them to over-indebtedness. The method to be used will be the deductive one and the research will be done in national bibliography.

Key-words: Cultural industry. Elderly consumer.Credit. Overindebtedness.

\section{INTRODUÇÃO}

A população brasileira está envelhecendo a passos largos. Nas últimas décadas, o que se percebe é um cenário de total transformação da pirâmide populacional brasileira. Se até a

\footnotetext{
${ }^{1}$ Mestrando em Direito, Políticas Públicas e Desenvolvimento Regional pelo Centro Universitário do Pará CESUPA. Graduado em Direito pela Universidade Federal do Pará. Juiz Federal Substituto do Tribunal Regional Federal da $1^{a}$ Região. Endereço eletrônico: carloschaves1980@uol.com.br.

2 Doutoranda em Direito pela Faculdade Autônoma de Direito - FADISP/SP e pela Universidade de Salamanca/ES. Mestranda e Doutoranda em Ciências Jurídicas pela Universidade Autónoma de Lisboa - UAL. Mestre em Direito pela Escola Paulista de Direito - EPD. Pós-Graduada em Processo Civil, Direito Civil e Direito do Consumidor e em Direito Notarial e Registral. Graduada em Direito pela Pontifícia Universidade Católica de São Paulo - PUC/SP. Tabeliã de Notas e Protesto de Letras Títulos em Ourinhos, Estado de São Paulo. Endereço eletrônico: ivypagliusi@ hotmail.com.

33 Mestranda em Direito, Políticas Públicas e Desenvolvimento Regional pelo Centro de Universitário do Estado do Pará - CESUPA. Pós-graduada em Direito Público e Processual Civil pela Estácio. Graduada em Direito pela Universidade Federal do Maranhão. Oficial de Registro de Imóveis no Estado do Pará. Endereço eletrônico: katiaborgess@hotmail.com.
} 
década de 80 do século passado, o Brasil era considerado um país de jovens, já se pode dizer que somos um país de maioria adulta em um caminho irreversível para uma maioria idosa.

Aliado ao fenômeno do envelhecimento da população nacional, tem-se hoje uma melhoria de aspectos econômicos, de saúde e de educação da população mais idosa. Se até poucas décadas atrás, tínhamos um cenário de quase exclusão do idoso como consumidor, hoje a população de mais idade se encontra verdadeiramente integrada no mercado do consumo, sendo destinatária de uma gama de produtos e serviços voltados exclusivamente a este nicho específico de consumidores, que cada vez mais vêm ganhando espaço social e empoderamento no mercado, muito em decorrência da estabilidade financeira proporcionada pelo gozo de benefícios previdenciários e assistenciais.

Consequência, portanto, quase que natural deste processo de inclusão da população idosa no mercado de consumo é o "bombardeio" de toda a espécie de propaganda produzida pela indústria cultural, voltada basicamente ao estabelecimento de padrões de comportamento interessantes ao grande capital.

Não são poucas as investidas para a manipulação de hábitos de consumo, criando-se um cenário de mistificação do hedonismo e de figurativização de uma responsabilidade financeira do idoso em relação aos demais integrantes da família.

Para vivenciarem tal mundo de encantamento mistificado pela indústria cultural, é que o acesso ao crédito é insistentemente fomentado aos idosos, apresentado como forma única e imprescindível de acesso ao modelo de vida idealizado.

O presente trabalho, portanto, terá como finalidade analisar se a indústria cultural, apreendida como técnica de imposição de comportamento no mercado de consumo, é capaz de levar os idosos, tidos aqui como consumidores hipervulneráveis, à aquisição de crédito irresponsável, de forma a conduzi-los ao superendividamento.

Para tanto, será dividido da seguinte forma, além desta introdução: no segundo capítulo, serão traçados comentários sobre o processo de envelhecimento da população brasileira e a evolução do idoso como esquecido pelo mercado para o status de consumidor protagonista; no terceiro capítulo, será analisada de que forma a indústria cultural se apresenta como técnica de manipulação das massas e como padronizadora de comportamentos; no quarto capítulo, serão feitas considerações sobre o perfil de consumo do idoso brasileiro e de que forma ele é determinado pela indústria cultural; no quinto capítulo, demonstrar-se-á que a 
aquisição de crédito irresponsável como instrumento para o idoso vivenciar a vida hedonista determinada pela indústria cultural é fator determinante ao seu superendividamento.

\section{O ENVELHECIMENTO DA POPULAÇÃO BRASILEIRA E O PROTAGONISMO DO CONSUMIDOR IDOSO HIPERVULNERÁVEL}

A população brasileira está envelhecendo. Se, em meados dos século passado, a pirâmide populacional era bem delineada, hoje já se pode falar em uma espécie de "retângulo populacional". Somos um país de adultos em um caminho irreversível para uma maioria idosa.

$\mathrm{Na}$ década de 40, as pessoas com idade superior a 60 anos no Brasil representavam pouco mais de $4 \%$ do total da população, número este que quase triplicou em pouco mais de cinquenta anos. Em 2011, tal percentual atingiu o patamar de $11 \%$, com estimativa de que seja de $27 \%$ em 2040. Anote-se que o período compreendido entre as décadas de 50 e 70 do século passado foi aquele em que o Brasil obteve o maior índice de fecundidade, observandose, em seguida, uma queda, o que indica que a natalidade no país não irá acompanhar pari passu o envelhecimento de sua população (CAMARANO, 2002, p. 5).

Outro dado relevante é que cerca de 55\% dos idosos brasileiros são do sexo feminino, sendo as mulheres as que têm a maior probablidade de ficarem viúvas, o que gera um maior declínio econômico-social, vez que ainda é o homem que, em regra, sustenta a família ${ }^{4}$.

São as mulheres também as que mais vivem, "sendo que a peculiaridade de apresentarem maior longevidade do que os homens acaba revelando maior debilitação física antes da morte, vindo a se tornarem mais dependentes de cuidados" (SHMITT, 2014, p. 93)

Segundo Camarano (2002, p. 6), no final da década de 90 do século passado, cerca de $12 \%$ das mulheres moravam em famílias sob a condição de "outros parentes”, , o que significa que, associado ao fato de que cerca de $75 \%$ das mulheres que vivem na condição de "outros parentes são viúvas, boa parte delas não possua experiência laboral formal e pouca educação

\footnotetext{
${ }^{4}$ Disponível em: https://www.otempo.com.br/interessa/comportamento/quase-30-milhoes-de-mulheres-chefiamos-lares-no-brasil-1.2034999. Acesso em: 14 de Jan. de 2020.

${ }^{5}$ Conforme Camarano (2002, p. 6), em que pese as mulheres viverem naturalmente mais do que os homens, estão mais sujeitas a doenças físicas e mentais.

${ }^{6}$ Ou seja, na condição de mães, sogras, irmãs ou outro tipo em relação ao chefe da família.
} 
formal, o que necessariamente representa uma maior necessidade de atenção por parte do Estado e da própria família.

Todavia, se por um lado a última fase da vida não é aquela em que se goza do ápice dos atributos físicos e mentais, por outro se pode falar que é a que, em média, apresenta as melhores condições financeiras se equiparadas com o restante da população ${ }^{7}$. De acordo com dados fornecidos pelo Serviço de Proteção ao Crédito (SPC), cerca de $66 \%$ dos idosos admitem que suas condições financeiras são melhores do que quando eram jovens, o que os torna uma importante engrenagem da força motriz da economia brasileira.

De acordo com Marques (2017)

\begin{abstract}
A importância dos idosos para a sociedade de consumo brasileira vem aumentando e muito. Em 2009, 64,1\% dos idosos no Brasil eram arrimos de família ou responsável principal pelo sustento da família, contribuindo com $52,9 \%$ da renda familiar. Em 2012, para um contingente de 23 milhões de pessoas idosas (12,6\% da população brasileira), em 6,5 milhões de famílias em que o idosos era o chefe [...] invertendo a tradicional relação de dependência apontada na literatura e tornando os idosos novos consumidores e, como alerta JohanesDoll, facilitando o crescimento de dívidas especialmente em contratos de crédito consignados
\end{abstract}

Dados do $\mathrm{SPC}^{8}$, referentes ao ano de 2012, indicam que os idosos de idade igual ou superior a 65 anos, que correspondem a 24,8 milhões de pessoas ou $13 \%$ da população nacional, foram responsáveis pela movimentação de 402,3 bilhões de reais.

Tudo isso se traduz não só em um exacerbado protagonismo como consumidores em cenário nacional, como também é terreno fértil para práticas agressivas de marketing voltadas à massificação de seus comportamentos de consumo pela indústria cultural.

Segundo Giovinazzo (2008, apud ARAÚJO et al, p. 58), o segmento de vendas voltado ao público da terceira idade representa um grande mercado e com disposição para consumir produtos e serviços de acordo com as suas necessidades e desejos, com indicativo de alta nos próximos anos ${ }^{9}$.

\footnotetext{
${ }^{7}$ Disponível em: https://www.spcbrasil.org.br/uploads/st_imprensa/spc_brasil_analise_ consumo_ terceira idade_2014.pdf. Acesso em 12 de nov. de 2019.

8 Disponível em: https://www.spcbrasil.org.br/uploads/st_imprensa/spc_brasil_analise_ consumo_ terceira idade_2014.pdf. Acesso em 12 de nov. de 2019.

${ }^{9}$ Segundo Araújo et al.(2015), em que pese seu grande potencial de consumo, apenas houve o seu definitivo reconhecimento pelo sistema econômico no início do século XXI. Até então, a este público o marketing e os produtos oferecidos se limitavam a bens voltados apenas a garantir a sua inserção no meio social, como, por exemplo, as fraldas geriátricas.
} 
Por outro lado, em que pese a sua importância no mercado de consumo brasileiro, os idosos, pelas próprias características da idade - embora suas condições possam variar muito de pessoa para pessoa - não se apresentam na mesma linha de vulnerabilidade ao do chamado consumidor médio ${ }^{10}$.

O natural avançar da idade tem como consequência a diminuição (ou perda) de determinadas aptidões físicas e mentais, que os tornam ainda mais vulneráveis nas relações negociais com os fornecedores, acentuando a necessidade de aquisição de certos bens e serviços, mormente àqueles voltados à saúde (MIRAGEM, 2016, p. 134).

São eles, portanto, dotados de uma fragilidade ainda maior ${ }^{11}$, podendo ser considerados como consumidores "hipervulneráveis".

Segundo Rosa, Bernardes, Félix (2017, p. 548), fatores como idade, enfermidade e outros tantos que resultam em maior fragilidade em relação ao consumidor mediano na exposição a produto ou serviço caracterizam elevação à inferioridade na relação consumerista, o que significa um maior grau de vulnerabilidade. Tal fragilização exacerbada é convencionalmente chamada de "hipervulnerabilidade".

E é neste cenário de envelhecimento da população brasileira, associado ao protagonismo do idoso como classe de elevado poder aquisitivo se comparada ao restante da população, que se torna imprescindível a pesquisa sobre se a potencial imposição do comportamento de consumo ao idoso hipervulnerável por via da indústria cultural é capaz de conduzir este nicho específico de consumidores a se comportar de maneira negativa a sua saúde financeira, adquirindo crédito de maneira impensada como um meio para se adaptar ao modelo imposto pelos padrões capitalistas.

\section{A INDÚSTRIA CULTURAL E A IMPOSIÇÃO DE HÁBITOS DE CONSUMO}

\footnotetext{
10 "[A velhice] é capaz de afetar não somente a vitalidade e a longevidade dos idosos a degeneração de funções físicas e biológicas, provocando também quadros de debilidade e afetação da capacidade de discernimento e raciocínio do homem médio, alçando o idoso à condição de maior suscetibilidade e vulnerabilidade em aspectos físicos, sociais e psíquicos. Nesse sentido, atividades usualmente classificadas como corriqueiras para o homem médio tornam-se mais penosas para o idoso, sobretudo no que se refere à capacidade de percepção apurada de atividades do trato civil, como exemplo a dificuldade de leitura associada à audição prejudicada e o raciocínio mais lento, típicas debilidades da fase senil; elas podem representar prejudicialidade ao idoso no ato de celebração de contrato para aquisição de um produto" (ROSA; BERNARDES; FÉLIX, 2017, p. 549).

${ }^{11}$ Nos termos do art. 39, IV, do CDC, "é vedado ao fornecedor de produtos ou serviços, dentre outras práticas abusivas: [...] prevalecer-se da fraqueza ou ignorância do consumidor, tendo em vista sua idade, saúde, conhecimento ou condição social, para impingir-lhe seus produtos ou serviços".
} 
De acordo com Canedo (2009), a definição de cultura, por envolver interesses multidisciplinares (sociologia, antropologia, história etc.), não é tarefa fácil. De toda forma, o termo origina-se da palavra latina "colore", possuindo múltiplos significados, como habitar, cultivar, proteger e honrar com veneração.

Somente no final do século XIX, é que o termo cultura adquire o significado figurado do senso comum hodierno, passando a designar o esforço despendido para o desenvolvimento das faculdades humanas. "Em conseqüência, as obras artísticas e as práticas que sustem este desenvolvimento passam a representar a própria cultura" (CANEDO, 2009). Para Canedo, três são as concepções básicas do termo, sendo que, para os objetivos do presente estudo, são interessantes apenas as duas primeiras: modos de vida que caracterizam uma coletividade ${ }^{12}$; obras e práticas da arte, da atividade intelectual e do entretenimento ${ }^{13}$; e fator de desenvolvimento humano.

Todavia, o que se vê em tempos de pós-modernidade ${ }^{14}$, em que tudo é tratado como produto, ao contrário de ser manifestação espontânea do grupo social, a cultura passa a ser reificada com propósito de lucro pelo sistema capitalista.

Segundo Coelho (1980), a cultura, neste contexto, passa a ser produzida de maneira industrial e em série, não mais como manifestação espontânea, crítica e de conhecimento, mas como qualquer produto consumível e trocável por dinheiro. Neste sentido, é feita de acordo com as necessidades e gostos do mercado e voltadas a um público que sequer tem tempo ou discernimento para questionar aquilo que consome.

Adorno e Horkheirmer (1985), neste ponto, desenvolvem a ideia do processo de desencantamento do mundo. Segundo os intelectuais alemães, o homem passa a substituir a imaginação pelo saber, a explicação mítica dos fenômenos naturais pelo esclarecimento.

\footnotetext{
12 "Vale nesta linha de continuidade a incorporação da dimensão antropológica da cultura, aquela que, levada às últimas consequências, tem em vista a formação global do indivíduo, a valorização dos seus modos de viver, pensar e fruir, de suas manifestações simbólicas e materiais, e que busca, ao mesmo tempo, ampliar seu repertório de informação cultural, enriquecendo e alargando sua capacidade de agir sobre o mundo. O essencial é a qualidade de vida e a cidadania, tendo a população como foco" (BOTELHO, 2007, p.110)

13 "A produção, distribuição e consumo de bens e serviços que conformam o sistema de produção cultural se tornou estratégica para o desenvolvimento das nações, na medida em que estas atividades movimentam uma cadeia produtiva em expansão, contribuindo para a geração de emprego e renda" (CANEDO, 2009).

${ }^{14}$ A pós-modernidade consiste no ambiente em que a sociedade pós-moderna está inserida, caracterizada pela globalização e domínio do sistema capitalista. Período em que o mundo e a natureza passam a ser percebidos por sua própria "complexidade, pela indeterminação e pela desordem, pelos riscos e pelas incertezas. A ordem racional buscada pela modernidade e o controle sobre a natureza, de que tanto o homem se orgulhava, desapareceram, cedendo espaço para o acaso e o risco" (AFONSO, 2013, p. 18). Esclarece Canto (2013, p. 183) que, simbolicamente, pode se considerar que a pós-modernidade se inicia com o fim da Segunda Guerra Mundial, momento em que há a derrocada do estado industrial e exposição das barbáries que se vivia até então.
} 
Esse processo de racionalização, todavia, tem origem no próprio mito, sob a forma de ciência positiva, da ideia de ascendência e superioridade do homem sobre a natureza, o que indica, paradoxalmente, que o conhecimento pode trazer instrumentos de dominação do homem civilizado pelo próprio homem, em "que a dominação da natureza volta-se contra o próprio sujeito pensante" (VERBICARO e SOARES, 2017, p. 110).

A dialética do mito e do esclarecimento acena à ideia de que o mito já é esclarecimento e o esclarecimento acaba por converter-se (e reverter-se) à mitologia. $\mathrm{O}$ aumento do poder passa a representar o substrato da dominação e a verdadeira alienação daquilo sobre o que se exerce o poder. $\mathrm{O}$ esclarecimento comporta-se tal qual o tirano se comporta em relação a seus subalternos. "Este [o ditador] conhece-os na medida em que pode manipulá-los. O homem de ciência conhece as coisas na medida em que pode fazê-las. É assim que seu em si torna para ele" (VERBICARO e SOARES, 2017, p. 111), confirmando a fé inabalável na capacidade do homem de dominar o mundo, bem como o retorno do esclarecimento à órbita do mito e a degeneração da fé em embuste e barbárie.

A indústria cultural, por assim dizer, seria o reflexo, ao mesmo tempo, do esclarecimento e da dominação do homem pelo homem. Seria, portanto, a responsável pela determinação de valores, comportamentos e, quanto ao consumo, a criação de hábitos prontos e impositivos ao indivíduo, desconfigurando a sua espontaneidade, reificando-a, de maneira que passa a ser imposta, não pelo seu destinatário, mas sim, de cima para baixo, pelo capital que lucra com a sua criação.

\footnotetext{
"Define-se indústria cultural como o conjunto de meios de comunicação, como o cinema, o rádio, a televisão, os jornais e as revistas, que formam um sistema poderoso para gerar lucros e por serem mais acessíveis às massas, exercem um tipo de manipulação e controle social, ou seja, ela não só edifica a mercantilização da cultura, como também é legitimada pela demanda desses produtos" (COSTA, 2003, apud CALAZANS; CAVALCANTI; LUCIAN, 2013, 204-205).
}

A manifestação da cultura, e, por conseguinte, a própria expressão do ser humano, é coisificada e entregue pelo capital como algo pronto, vazio, alienante, e de interesse financeiro de seu criador. Em que pese a artificial liberalidade das sociedades pós-modernas, "os mecanismos da indústria cultural exercem uma profunda influência sobre os indivíduos, 
controlando os seus comportamentos e as suas escolhas" (ADORNO; HORKEIMER apud DAVIES; NUNES, 2014) ${ }^{15}$.

\begin{abstract}
Dentre as consequiências advindas com o impacto da técnica, encontra-se o desenvolvimento de mecanismos de controle das consciências individuais e coletivas, exercido pela imprensa, rádio e cinema, denominado de indústria cultural. Longe de sugerir a idéia de cultura produzida espontaneamente pelas massas, a indústria cultural impõe-se de cima para baixo, com a finalidade de homogeneizar, adaptar e integrar as massas aos valores capitalistas de consumo. Para tanto, implementou um vasto processo de racionalização dos procedimentos de produção, padronização e difusão dos produtos culturais, em que os modelos são fornecidos a priori pela probabilidade de lucro, bilheteria e sucesso de mercado e não pela qualidade intrínseca da obra artística considerada em sua autonomia, em seu valor e em sua singularidade(VERBICARO e SOARES, 2017, p. 112-113).
\end{abstract}

Neste cenário de forte influência da indústria cultural na determinação da forma de se comportar, de imposição de valores e, especialmente, de criação de hábitos de consumo das pessoas, o que se percebe é que elas são transformadas naquilo que o sistema econômico as força a ser ${ }^{16}$. Estão tão contaminadas pelos esquemas da indústria cultural e sua exploração sistemática e programada de bens culturais para fins comerciais, que passam a buscar incessantemente uma vida que corresponda exatamente ao modelo padrão apresentado.

Como consequência, o que há é uma busca compulsiva e desenfreada pela aquisição das mercadorias da "sociedade industrial e de consumo e a naturalização de sua linguagem a ponto de criar um repertório de gestos padronizados e estigmatizados" (VERBICARO e SOARES, 2017, p. 113).

Para todos algo está previsto; para que ninguém escape, as distinções são acentuadas e difundidas. $\mathrm{O}$ fornecimento ao público de uma hierarquia de qualidade serve apenas para uma quantificação mais complexa. Cada qual deve se comportar, como espontaneamente, em conformidade com o seu level, previamente caracterizado por

\footnotetext{
${ }^{15}$ Ressalte-se a importância do elemento tempo para a indústria cultural. Na modernidade (e posteriormente em pós-modernidade), o que se tem é uma verdadeira diferenciação do tempo destinado ao trabalho para o tempo destinado ao lazer. O tempo livre surge como uma válvula de escape da coisificação sofrida pelo trabalhador em seu dia a dia de labuta. É o momento do dia em que o indivíduo se "desliga" para que, no dia seguinte, possa voltar à labuta com a sua energia renovada. E é exatamente nestas horas de ócio que se consomem os bens de entretenimento e lazer. Todavia, é neste tempo de "não se fazer nada" que o indivíduo é bombardeado por opções de entretenimento, "o que gera a necessidade da existência de algo que possa atender a esses desejos em grande escala: a indústria cultural. É importante destacar que pela sua produção grosseira de produtos idênticos para atender a demanda, a indústria cultural acaba por transformar, como afirma Adorno (2002), o tempo livre em uma paródia do seu conceito. [...] a indústria cultural tornou-se um mecanismo bem mais desenvolvido que inclui, como afirma Adorno (2002), o controle dos meios de comunicação de massa dos ideais da classe dominante" (CALAZANS; CAVALCANTI; LUCIAN, 2013, 205-206).

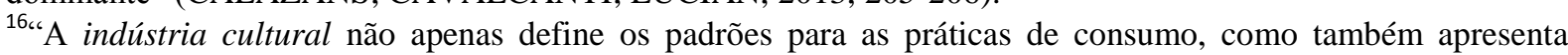
estratégias para a imposição de valores e ideologias, e aqueles que não seguirem aos padrões impostos tendem à possibilidade de exclusão social" (DAVIES; NUNES, 2014).
} 
certos sinais, e escolher a categoria de produtos de massa fabricada para seu tipo (ADORNO; HORKEIMER, 1985).

E é, portanto, neste cenário, em que se padronizam os gostos, a cultura, o comportamento e o próprio ato de consumir das pessoas, sempre a serviço do sistema econômico, que se mostra absolutamente necessário o estudo se (e de que forma) a indústria cultural é capaz de influenciar comportamentos negativos por parte de um específico nicho de consumidores hipervulneráveis, os idosos, em especial no que diz respeito à aquisição de crédito como meio para se alcançar um padrão e estilo de vida posto e determinado pelo mercado.

\section{O PERFIL DE CONSUMO DO IDOSO BRASILEIRO E A INDÚSTRIA CULTURAL}

Conforme já dito, a população brasileira encontra-se em tendência definitiva para o envelhecimento, não havendo perspectiva de que os índices de natalidade se repetirão na mesma velocidade.

Todavia, se antes o avançar da idade era sinônimo de decrepitude, no século XXI, o que se observa é uma mudança total de perfil: os idosos estão cada vez mais conectados, conscientes, empoderados financeiramente e ávidos ao consumo de produtos e serviços que ultrapassem àqueles apenas voltados à sua inserção social.

Apresentam-se no mercado de consumo dispostos a adquirirem bens e serviços destinados ao prazer, ao lazer e ao conhecimento, em absoluta distinção daquele velho senil cuja imagem se perdeu no século passado.

A idade para as pessoas que ultrapassaram a faixa de 60 anos não mais significa estar velho. É muito mais encarada como uma fase da vida de acúmulo de experiência e de espírito positivo. Os idosos de hoje são muito mais ativos e independentes do que aqueles de algumas décadas atrás.

Segundo dados do Serviço de Proteção ao Crédito e Confederação Nacional dos Dirigentes Lojistas ${ }^{17}$, mais de oitenta por cento dos idosos relatam aspectos positivos sobre a terceira idade, sendo que, em uma escala de zero a dez, a sensação de felicidade é de oito ou

\footnotetext{
${ }^{17}$ Disponível em: https://www.spcbrasil.org.br/wpimprensa/wp-content/uploads/2018/09/SPC-AnaliseTerceira_Idade_Estilo-de-Vida-e-Consumo-1.pdf. Acesso em 11 de nov. de 2019.
} 
mais, para pelo menos $61 \%$ deles. E os idosos não pensam em morrer logo, o que indica que seus planos de vida consumista pós-sessenta anos são planejados para longo prazo. Para quase $60 \%$ deles, a impressão sobre a expectativa de vida é de quase 90 anos (89,6 anos).

No que diz respeito aos hábitos de consumo ${ }^{18}$, tem-se que, para se sentirem mais bonitos e confiantes, $26 \%$ utilizam cremes e produtos para o corpo, $22 \%$ compram roupas, sapatos e acessórios, e 17\% tomam vitaminas, chás e colágenos. E, quando o assunto é o que fazem nos momentos de lazer para se distrair e divertir, os hábitos dos idosos são também diversos daqueles de gerações passadas. Para 59\%, o tempo livre é destinado a assistir à televisão, 30\% navegam na internet, $27 \%$ costumam ler livros, e 25\% costumam viajar.

O que a percepção sobre a própria questão da idade e as modificações dos hábitos indica é que os idosos do século XXI se caracterizam como um nicho particular no mercado de consumo, possuindo necessidades específicas e diversas dos consumidores mais jovens, ao mesmo tempo em que se encontram conectados e receptivos aos velhos e novos instrumentos da indústria cultural e, portanto, expostos à massificação de comportamento dela consequente.

Se, antes, os idosos gastavam o último terço de suas vidas em práticas de lazer e de consumo desinteressantes ou pouco interessantes ao mercado, hoje são consumidores conectados aos novos instrumentos de comunicação e ávidos ao consumo de bens e serviços voltados ao lazer e ao prazer.

E se, por um lado, o acesso à internet e aos mais diversos instrumentos de comunicação abrem as portas ao conhecimento e a informações, por outro, expõem os idosos a práticas agressivas de marketing, informação seletiva e desinformação decorrentes da indústria cultural, o que faz com que seus hábitos de consumo sejam manipulados de forma inclusive a determinarem comportamentos prejudiciais a sua saúde financeira, levando-os, por conseguinte, ao superendividamento.

De acordo com estudo realizado por Araújo et al (2015) sobre o marketing desenvolvido em diversos instrumentos da indústria cultural voltados aos idosos, destaca-se a técnica de sua "figurativização", que os apresentam em esquemas narrativos simulacros da realidade, que simboliza o ambiente social em que vivem.

A observação do corpus, independente da categorização dos anúncios por segmentos de produtos/serviços, revela que a grande maioria das imagens apresenta idosos em

\footnotetext{
${ }^{18}$ Disponível em: https://www.spcbrasil.org.br/wpimprensa/wp-content/uploads/2018/09/SPC-AnaliseTerceira_Idade_Estilo-de-Vida-e-Consumo-1.pdf. Acesso em 11 de nov. de 2019.
} 
situação de lazer e de fruição descomprometida do tempo. Tais figuras refletem, logicamente, os temas gerais das narrativas dos anúncios que se baseiam na premissa de que a dita "terceira idade" seria o período para desfrutar das conquistas de uma vida plena de trabalho e de dedicação à família. Portanto, produtos e serviços relacionados a cuidados com a estética e a saúde, turismo e serviços financeiros (em especial oferta de crédito) surgem como soluções que auxiliam e dão suporte para a fruição do tempo (ARAÚJO; CASOTTI; SILVA; PESSÔA, 2015 , p.77) ${ }^{19}$.

Constrói-se, portanto, nesta narrativa, uma imagem dos idosos (geralmente apresentado em parques, shoppings, praias e em outros ambientes voltados ao lazer) de total desvinculação com o universo do trabalho e das responsabilidades do dia a dia, indicando que podem e devem desfrutar de um mundo de prazer e ser recompensados pelas conquistas realizadas ao longo de uma vida toda de trabalho, ao mesmo tempo em que a eles são ofertados produtos e serviços relacionados a cuidados com a estética, a saúde e ao turismo. Trabalham-se muito mais os aspectos hedônicos dos produtos e serviços do que propriamente as suas utilidades.

E, quando o assunto se relaciona à publicidade de produtos e serviços financeiros, segundo Barros (2008, apud ARAÚJO; CASOTI, PESSOA; SILVA, 2015), a figura do idoso é relacionada a temáticas de decadência/inatividade, experiência/competência e liberdade/divertimento/ausência de obrigações ou compromissos.

Doll e Cavallazzi (2016) destacam que o crédito consignado é estimulado à população idosa principalmente através de um sistema de marketing agressivo, financiado pelos bancos, nos quais, associada à publicidade normal, são empregados clipes televisivos em que conhecidos atores, também já idosos, aconselham o "credito amigo" aos aposentados.

Nestas campanhas, diversas técnicas de manipulação promovidas pela indústria cultural são desenvolvidas. Retira-se, por um lado, o limite entre a esfera econômica e o interesse privado através do chamado "crédito amigo", por outro, "desculpabiliza-se" o crédito através de manipulação de sentimentos característicos da terceira idade, como solidão

\footnotetext{
${ }^{19}$ Tal reprodução da realidade, segundo Adorno e Hokeimer (1985), não passa de mais uma técnica de manipulação das massas e determinação de comportamento: "Quanto maior a perfeição com que suas técnicas duplicam os objetos empíricos, mais fácil se torna hoje obter a ilusão de que o mundo exterior é o prolongamento sem ruptura do mundo que se descobre no filme. Desde a súbita introdução do filme sonoro, a reprodução mecânica pôs-se ao inteiro serviço desse projeto. A vida não deve mais, tendencialmente, deixar-se distinguir do filme sonoro. Ultrapassado de longe o teatro das ilusões, o filme não deixa mais a fantasia e ao pensamento dos espectadores nenhuma dimensão na qual estes possam, sem perder o fio, passear e divagar no quadro da obra fílmica permanecendo, no entanto, livres de controle de seus dados exatos, e é assim precisamente que o filme adestra o espectador entregue a ele para se identificar imediatamente com a realidade".
} 
e saúde. Por fim, utilizam-se da autoridade de pessoas famosas para fins de manipular a vontade e a necessidade de consumo e aquisição do crédito.

Assim, o que se conclui é que, ao mesmo tempo em que se observa um maior empoderamento e protagonismo do consumidor idoso no século XXI, com anseios, exigências e necessidades próprias, tem-se uma maior exposição às práticas do mercado, em especial àquelas impostas pela indústria cultural de manipulação de hábitos de consumo, o que é capaz de conduzi-los a comportamentos negativos à sua saúde financeira, fundamentalmente quando, para gozarem da vida hedônica proposta, adquirem produtos e serviços ofertados pelo sistema financeiro.

O item seguinte será destinado à análise da aquisição de crédito irresponsável pelos consumidores idosos e de que forma isto é capaz de levá-los ao superendividamento.

\section{O CRÉDITO IRRESPONSÁVEL E O SUPERENDIVIDAMENTO DOS IDOSOS}

O termo superendividamento tem origem na doutrina francesa e corresponde a uma impossibilidade de o devedor de boa-fé, considerando o seu poder aquisitivo e os meios normais de pagamento, saldar o montante de suas dívidas (BORGES, 2018, p. 97) ou a “impossibilidade de pagamento de dívidas contraídas por um tomador de crédito, geralmente o consumidor de boa-fé, no momento de seu vencimento ou a partir do momento em que o débito tornar-se exigível por parte do credor" (OLIVEIRA, 2016, p. 92).

É uma neologia formada pela palavra "sur" (que significa super, excesso, sobrecarga) com a palavra endividamento, que significa o excesso de carga debitória que é impossível de pagar diante da renda existente e que pode comprometer a sobrevivência da pessoa.

Costuma-se ainda diferenciar o superendividamento ativo do passivo, sendo que aquele é fruto da aquisição de produtos e serviços de maneira descomedida e sem responsabilidade financeira, e este ocorre quando o consumidor não contribui diretamente para que aconteça, sendo mais o resultado de situações alheias a sua vontade, como, por exemplo, situação de desemprego e doença na família, dentre outras. 
No que diz respeito aos consumidores idosos, já se abordou que eles, em que pese o seu empoderamento no mercado de consumo, vêm sendo bombardeados com repetidas campanhas de massa orquestradas pelos mais diversos meios de comunicação representantes da indústria cultural, o que faz com que, tal como as demais massas de consumidores, passem a se submeter a hábitos de consumo compatíveis com os interesses do mercado..

A imagem da figura do idoso do século XXI construída pela indústria cultural (de responsável financeiro de familiares, de ser a terceira idade aquela em que se deve aproveitar o estilo de vida hedonista etc.) tem um custo, um valor, o qual quase sempre apenas é alcançado através da aquisição de créditos impagáveis junto a instituições financeiras. Endivida-se para usufruir do estilo de vida imposto.

Enfim, cria a indústria cultural um modelo padrão de comportamento dos idosos, com valores e hábitos voltados ao consumo, oferece-lhes uma gama de serviços e bens voltados justamente para suprir estas necessidades fictícias, ao mesmo tempo em que, para serem realizadas (já que possuem um custo), as instituições financeiras se encarregam de adiantar substancial crédito a ser pago mediante longas e intermináveis prestações.

Todavia, como a maioria dos idosos tem como fonte única de renda o benefício previdenciário ou assistencial correspondente ao valor do salário mínimo, qualquer parcela destinada ao pagamento de dívidas de crédito já lhes subtrai soma importante à sua manutenção, prejudicando, enfim, a sua própria sobrevivência mensal e criando verdadeiro obstáculo à quitação de suas dívidas.

Para se estimar o grau de endividamento dos idosos brasileiros juntos às instituições de crédito, segundo dados informados pela revista eletrônica Estado de Minas ${ }^{20}$ (reportagem datada de 06/03/2017), de cada dez beneficiários do INSS, pelo menos seis estão endividados por meio de apenas uma modalidade de crédito, o consignado. São aproximadamente 20,05 milhões de aposentados e pensionistas brasileiros com algum tipo de consignação em folha, montante de comprometimento que deve ser muito maior, eis que o INSS não consegue obter informações de outros tipos de contratos de empréstimos, como, por exemplo, os com desconto em conta em dia certo. O montante da dívida chega ao estratosférico valor de 102,3

\footnotetext{
${ }^{20}$ Disponível em: https://www.em.com.br/app/noticia/economia/2017/03/06/internas_economia,851853 /aposentados-e-pen sionista s-estao-sufocados-pelo-credito-consignado.shtml. Acesso em: 12 de nov. de 2019.
} 
bilhões de reais ${ }^{21}$, o que significa dizer que cada endividado, considerando apenas o crédito consignado em folha, deve, em média, R\$ 5.104,46.

Tal grau de endividamento junto às instituições de crédito tem um custo social seriíssimo: a total incapacidade dos idosos de adimplirem suas dívidas, o que acarreta diminuição de sua capacidade de consumo, de aquisição de produtos e serviços básicos para a sua sobrevivência e, enfim, verdadeira exclusão social.

Segundo reportagem do jornal eletrônico Estadão $^{22}$, a inadimplência dos idosos é a que mais cresce no País, passando de 8,7 milhões para 9,7 milhões apenas no período de maio de 2018 a maio de 2019, ou seja, um aumento de 9,3\% no intervalo de apenas um ano, percentual este bem superior se comparado ao aumento do grau de inadimplência do restante da população $(2,2 \%)$, sendo o principal motivo, justamente, o chamado crédito consignado.

Segundo Marques (2017), o grau de endividamento dos idosos tem inclusive reflexo em ações judiciais. Em pesquisa empírica realizada pelo Projeto Piloto TJ/RS, sob a coordenação das magistradas Káren Bertoncello e Clarissa Costa, levantou-se que, nos cinco anos de duração do projeto (2007/2012), das 3.225 audiências de consumidores superendividados, $18,5 \%$ eram de idosos, ou seja, percentual muito maior do que a parcela de idosos da população brasileira (cerca de $13 \%$ ou 26 milhões de idosos).

Dos dados apresentados, pode-se dizer que a inadimplência e o superendividamento dos idosos brasileiros são uma realidade diretamente relacionada à contratação de crédito, mas suas causas mais profundas podem ser encontradas justamente na massificação de práticas de consumo determinadas pela indústria cultural a que estão expostos, a qual, ao tempo que os empoderam, condiciona-os a comportamentos voltados ao hedonismo, ao consumo desenfreado ou a assumir responsabilidades decorrentes de sua pseudo-condição de esteio de família.

\section{CONCLUSÃO}

Observou-se que os idosos vêm ocupando cada vez mais uma posição de protagonismo no mercado de consumo, talvez nunca antes presenciada na história de nosso País.

\footnotetext{
${ }^{21}$ O valor atualizado do montante da dívida gira, em dados atualizados a maio de 2019, em torno de 133 bilhões de reais, ou seja, aumento de mais de trinta bilhões de reais em aproximadamente dois anos.

${ }_{22}$ Disponível em: https://economia.estadao.com.br/noticias/geral,inadimplencia-entre-idosos-e-a-que-maiscresce-no-pais,70002906845. Acesso em 12 de nov. de 2019.
} 
O idoso da atualidade, seja em relação a necessidades, seja em relação à perspectiva quanto ao futuro, não pode ser nem de longe mais comparado ao idoso do século passado. Hoje, percebe-se que as pessoas da terceira idade são mais dispostas, investem no futuro e se inserem na sociedade de maneira muito mais inclusiva a de outrora. $\mathrm{O}$ idoso não mais passa os últimos anos de sua existência na terra esperando a morte, mas sim goza deste último terço de vida de maneira mais ativa, em busca de conhecimento e experiências novas, não vivenciadas em outros momentos de sua vida.

Concomitantemente a esse novo modelo de vida assumido pelos idosos, tem-se que eles, quer em razão de serem os principais destinatários de benefícios previdenciários e assistenciais, quer em razão do resultado mesmo de uma vida inteira de acumulação de patrimônio, encontram-se, se comparados aos demais integrantes da população brasileira, em situação financeira relativamente boa, o que resulta em maior empoderamento no mercado de consumo.

Tal protagonismo, todavia, não passou despercebido pelos fornecedores de bens e serviços, nem pela indústria cultural. Maciças campanhas publicitárias hoje estão sendo criadas e direcionadas especificamente aos idosos, voltadas ao estímulo e à padronização de hábitos consumistas, muitas vezes perniciosos à saúde financeira deles.

Os idosos, seja pelas próprias características da idade, seja pela necessidade de aquisição de determinados produtos e serviços necessários a sua inserção social, seja, enfim, pelo protagonismo recente no mercado de consumo, mostram-se mais débeis em resistir às violações aos seus direitos de livre escolha de consumo. Pode-se dizer, portanto, que, em comparação ao consumidor médio, sua vulnerabilidade é agravada. São eles hipervulneráveis.

Valoriza-se o consumo hedonista, irresponsável e absolutamente despreocupado com o futuro da população mais velha. Estimula-se o gozo da vida imediato pelos idosos, como se estes, dada a melhora das suas condições de uma maneira em geral, não tivessem uma perspectiva ainda longa de vida. Figurativizam-se os idosos como esteio de suas famílias, ao mesmo tempo em que se criam responsabilidades em relação à educação e ao sustento de filhos e netos.

E é exatamente para se dar conta deste novo modelo de vida imposto e de novas responsabilidades figurativizadas em relação a familiares, que a oferta de crédito é apresentada como a solução ideal. 
O que se demonstrou, todavia, é que é justamente o "remédio", ou seja, o crédito, oferecido como solução para levarem a vida idealizada pela indústria cultural, a principal causa do superendividamento dos idosos.

Como se observou ao longo do desenvolvimento do presente trabalho, o percentual de endividados idosos vem crescendo exponencialmente e de maneira muito superior se comparada ao restante da população, sendo justamente a aquisição do crédito irresponsável seu principal motivo.

O resultado do superendividamento da população mais velha brasileira é um cenário crescente e irreversível de exclusão social e econômica, com potencialidade de afetar inclusive a sua própria saúde psiquiátrica e, por conseguinte, gerando irremediáveis consequências públicas e sociais.

\section{REFERÊNCIAS BIBLIOGRÁFICAS}

ADORNO, Theodor; HORKHEIMER, Max. Dialética do Esclarecimento. Rio de Janeiro: Zahar, 1985.

AFONSO, Luiz Fernando. Publicidade abusiva e proteção do consumidor idoso. São Paulo: Atlas. 2013.

ARAÚJO, Fábio Francisco de; CASOTI, Letícia Moreira; SILVA, Renata Céli Moreira da; PESSÓA, Luis Alexandre Grubts de Paula. O consumidor de terceira idade na primeira década do século XXI: uma análise da propaganda dirigida a idosos. Revista Administração em Diálogo. São Paulo, v. 17, n.1, Jan/Abr. 2015, p. 54-85.

BORGES, João Paulo Resende. O Superendividamento no Brasil: um estudo sob a ótica da Análise Econômica do Direito. Revista da Procuradoria Geral do Banco Central. Brasília, v. 12, n. 2, Dez. 2018, 95-109.

BOTELHO, Isaura. Dimensões da cultura e políticas públicas. São Paulo em Perspectiva, São Paulo, v. 15, n. 2, 2001. Disponível em: http://www.scielo.br/scielo.php?script=sci_ arttext\&pid=S0102-88392001000200011\&lng=e m\&nrm=iso. Acesso em: 05/11/2019.

CALAZANS, Janaína de Holanda Costa; CAVALCANTI, Gêsa Karla; LUCIAN, Rafael. O uso de redes sociais segmentadas na promoção de produtos culturais: uma análise do caso getglue. Revista Interamericana de Comunicação Midiática. V. 12 n. 14, 2013, p. 202-213. CAMARANO, Ana Amélia. Envelhecimento da população brasileira: uma contribuição demográfica. Instituto de Pesquisa Econômica Aplicada, 2002. 
CANEDO, Daniele. "Cultura é o quê?" - reflexões sobre o conceito de cultura e a atuação dos poderes públicos. V ENECULT - Encontro de estudos multidisciplinares em cultura, 2009.

CANTO, Rodrigo Eidelvein do. Direito do consumidor e vulnerabilidade no meio digital. Revista Direito do Consumidor. São Paulo, v. 87, p. 179-209, mai./jun. 2013

COELHO, Teixeira. O que é indústria cultural. Coleção primeiros passos. Brasília: Brasiliense, 1980.

DAVIES, Lorenice Freire; NUNES, Denise Silva. A influência da indústria cultural no consumo e o papel da educação ambiental para a promoção do consumo sustentável. Anais da semana acadêmica FADISMA ENTREMENTES. 11 ed. Santa Maria, 2014.

DOLL, Johannes; CAVALLAZZI, Rosangela Lunardelli. Crédito Consignado e Superendividamento dos Idosos. Revista Direito do Consumidor. v. 107, set./.out, 2016. Disponível em:http://www.mpsp.mp.br/portal/page/portal/documentacao_e_divulgacao/do c_biblioteca/bibli_servicos_produtos/bibli_boletim/bibli_bol_2006/RDCons_n.107.11.PDF

MARQUES, Cláudia Lima. A proteção do idosos consumidor: diálogo das fontes para proteger o idoso e prevenir o superendividamento. In: LEITE, G. S; Leite G. S; Mendes, G. F; Mudrovitsch, R. B. Manual dos Direitos da Pessoa Idosa. São Pulo: Saraiva, 2017.

MIRAGEM, Bruno. Curso de Direito do Consumidor. 6 ed. Ver, atual. eampl. - São Paulo: Revista dos Tribunais, 2016.

OLIVEIRA, Felipe Guimarães. O superendividamento na sociedade brasileira e os desafios para uma tutela jurídica-econômica de proteção ao consumidor no século XXI. Dissertação. (Mestrado na área de Direito, Políticas Públicas e Desenvolvimento Regional) - Centro Universitário do Estado do Pará, Belém, 2016. Disponível em: https://www.cesupa.br/MestradoDireito/dissertacoes.asp.

PEDREIRA, Adalto; OVALLE, Carolina; DUTCOVSKY, Caroline; IVANTES, Juliana; MORTEAN, Lais; BOURROUL, Leonardo; XANTHOPOYLOS, Marcelle; PALMIERI, Maria de Lourdes; FERRARI, Sthefanny; PEIXOTO, Thais. Consumo e Identidade: Reflexão sobre a indústria cultural e sua influência no cotidiano. Psicologado. Edição 08/2011. Disponível em: https://psicologado.com.br/psicologia-geral/consumo-e-identidadereflexao-sobre-a-industria-cultural-e-sua-influencia-no-cotidiano . Acesso em 11 Nov 2019.

ROSA, Luiz Carlos Goiabeira; BERNARDES, Luana Ferreira; FÉLIX, Vinícius César. O idoso como consumidor hipervulnerável na sociedade de consumo pós-moderna. Revista Jurídica da Presidência. Brasília, v. 18, n. 116, p. 533-558, out.2016/jan.2017.

SCHMITT, Cristiano Heineck. Consumidores hipervulneráveis: a proteção do idoso no mercado de consumo. São Paulo: Atlas, 2014. 
SOARES, Dennis Verbicaro; VERBICARO, Loiane da Ponte Souza Prado. A indústria cultural e o caráter fictício da individualidade na definição de consumidor-comunidade global. Revista Jurídica Cesumar. Maringá, v. 17, n.1, p. 107-131, jan./abr. 2017. 